\title{
MAPEAMENTO DO PMCMV FAIXA 1 E DOS VAZIOS URBANOS INTERSTICIAIS ENTRE ILHÉUS E ITABUNA, BA
}

\author{
AUTOR: CALLINE CHAVES DE JESUS \\ CO-AUTOR/ORIENTADOR: SILVIA KIMO COSTA
}

Resumo: O termo Habitação de Interesse Social (HIS) refere-se a uma série de soluções de moradia voltadas para a população de baixa renda e estão diretamente relacionadas ao Déficit Habitacional, que pode ser entendido como, déficit por reposição de estoque e déficit por incremento de estoque de moradias. Entretanto no Brasil, o padrão arquitetônico das HIS além de não considerar a diversidade de realidades da população demandante, não contemplam inovações no design e estratégias que possibilitam eficiência energética como também a zona em que essas habitações serão construídas. Considerando o exposto, o objetivo desta Pesquisa foi fazer o mapeamento do PMCMV Faixa 1 (de 0 a 3 salários-mínimos) e os vazios urbanos intersticiais entre llhéus e Itabuna, BA. Tomou-se como estudo de caso as habitações do Programa Minha Casa Minha Vida, situadas no município de llhéus e Itabuna. O mapeamento foi analisado segundo a localização de cada habitação, procurando sua zona, bairro e município e a partir disso analisou-se a distância entre a zona e o centro urbano. Utilizou-se o Google Earth para obter imagens e a visão geral dos municípios e das HIS e foi realizada visita de campo. Identificou-se os Conjuntos Habitacionais que foram construídos em Ilhéus e Itabuna, BA entre os anos de 2011 e 2016.

Palavras-chave: Mapeamento, PMCMV, Habitação de Interesse Social. 